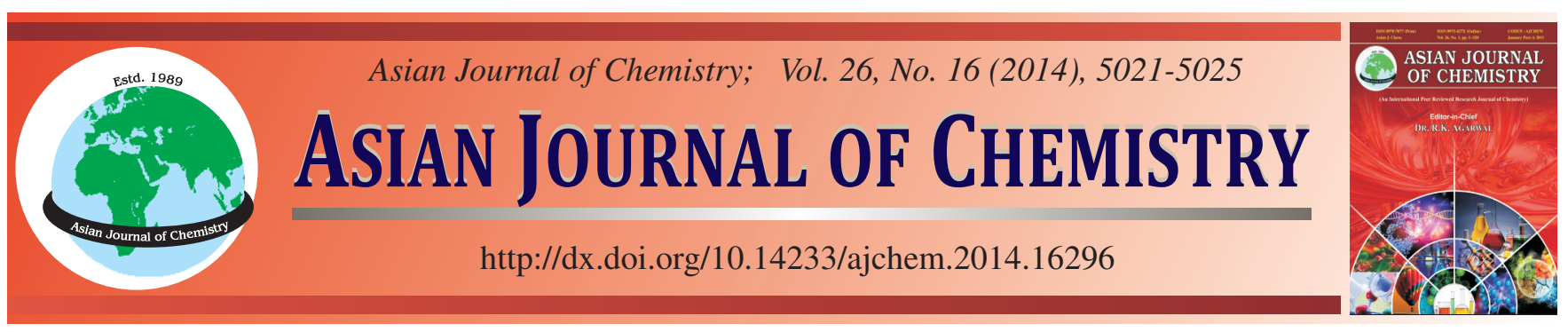

\title{
Cloud-Point Extraction and Fluorospectrophotometric Determination of Rhodamine B in Water Samples
}

\author{
Jun-Chen You, Hao Wu, Li-Ming Du* and Yun-Long Fu
}

Analytical and Testing Center, Shanxi Normal University, Linfen 041004, Shanxi Province, P.R. China

*Corresponding author: Tel/Fax: +86 357 2057969; E-mail: 1md@dns.sxnu.edu.cn

\begin{abstract}
A new micelle-mediated cloud point extraction method is described for the sensitive and selective determination of trace amounts of Rhodamine B by fluorospectrophotometry. The method is based on the cloud point extraction of Rhodamine B from aqueous solutions using [sodium dodecyl benzene sulfonate (SDBS)] anionic surfactants in neutral media. The method does not require any organic solvent in the extraction process. The extracted surfactant-rich phase is diluted with methanol and its fluorescence intensity is measured at $547 \mathrm{~nm}$ using a fluorospectrophotometer. The effects of different operating parameters such as the concentrations of surfactant and salt, temperature and $\mathrm{pH}$ on the cloud point extraction of Rhodamine B are studied and a set of optimum conditions are determined. Under the optimum conditions, a linear calibration graph ranging within $0.02-14 \mathrm{ng} / \mathrm{mL}$ of Rhodamine $\mathrm{B}$ in the initial solution with $\mathrm{r}=0.9992(\mathrm{n}=5)$ is obtained. The detection limit based on three times the standard deviation of the blank (3Sb) is $0.006 \mathrm{ng} / \mathrm{mL}(\mathrm{n}=11)$ and the relative standard deviation for $10 \mathrm{ng} / \mathrm{mL}$ of Rhodamine B is $3.1 \%(\mathrm{n}=5)$. The method is used to detect Rhodamine B in a tap water sample and a contaminated water sample from a dyestuff factory.
\end{abstract}

Keywords: Rhodamine B, Sodium dodecyl benzene sulfonate, Cloud-point extraction, Spectrofluorometry.

\section{INTRODUCTION}

Rhodamine-B [9-(2-carboxyphenyl)-3,6-bis(diethylamino)xanthylium chloride] is widely used as a fabric dye and as pigment in drug and cosmetic preparations ${ }^{1}$. RhodamineB (Fig. 1) has a chemical structure that fits in the class of xanthene dyes and is extremely water soluble ${ }^{2}$. This dye is used as a colorant in textiles and foodstuffs and is also a wellknown fluorescent water tracer. Rhodamine-B is harmful if swallowed by humans and animals and causes irritation to the skin, eyes and respiratory tract. Thus, given these hazardous and harmful effects, a simple method for determining Rhodamine-B in different samples must be developed ${ }^{3-6}$.<smiles>CCCCN(CC)c1ccc2c(c1)OC1=CC(=[N+](CC)CCC)C=CC1C2c1ccccc1C(=O)O</smiles>

Fig. 1. Chemical structure of Rhodamine-B
Various methods for the separation and determination of Rhodamine-B have been proposed, such as microscopies ${ }^{7}$ liquid-liquid microextraction ${ }^{8}$ high-performance liquid chromatography ${ }^{9-11}$ solid-phase extraction ${ }^{12-14}$ and spectrophotometry ${ }^{15,16}$. Most of these methods use organic solvents, require expensive instruments, need strictly controlled reaction conditions and involve time-consuming steps. Some actual techniques have inadequate sensitivity or require a sample pretreatment to isolate the dye from the matrix. Therefore, a simple, highly sensitive and highly selective method such as spectrofluorimetry must be established for the determination of Rhodamine-B.

Cloud-point extraction (CPE) is based on the phase behaviour exhibited by aqueous solutions of non-ionic surfactants that become turbid after increased temperature or after adding additives such as salting-out electrolytes ${ }^{17-19}$. At a certain temperature, an aqueous solution of a non-ionic surfactant separates into two phases. The first layer is a surfactantrich phase containing a high concentration of surfactant and has a smaller volume than the solution. The second layer is the aqueous phase containing a low concentration of surfactant. This temperature is known as the cloud-point temperature (CPT) of the surfactant ${ }^{20}$. The solute molecules present in the aqueous solution of a non-ionic surfactant is distributed between the two phases above the $\mathrm{CPT}^{21}$. Separations based 
on the cloud-point phenomenon have been performed using Triton X-100 by UV-spectrophotometry to extract RhodamineB from different samples ${ }^{15}$. However, this surfactant has a high cloud point $\left(78^{\circ} \mathrm{C}\right)$, thereby causing losses in extraction efficiency because the temperature decreases during centrifugation.

Among all spectroscopic techniques, spectrofluorimetry is well suited to be used in combination with multi-component analysis because relatively few compounds having intrinsic fluorescence. This fact, combined with the possibility of changing either the excitation wavelength, emission wavelength, or both simultaneously, greatly increases the selectivity of spectrofluorometric methods. Additionally, detection limits can often be improved simply by increasing the intensity of radiation used for excitation ${ }^{22}$.

To the best of our knowledge, no attempt has been made to combine anionic [sodium dodecyl benzene sulfonate (SDBS)] surfactant-based CPE with spectrofluorometry for the preconcentration and determination of dyes. This study aimed to establish a CPE method of detecting Rhodamine-B that uses only anionic (SDBS) surfactants in the presence of an electrolyte $\left(\mathrm{MgCl}_{2} \cdot 6 \mathrm{H}_{2} \mathrm{O}\right)$, followed by fluorometric determination. The cloud point of SDBS is close to room temperature; hence, as an alternative to other methods requiring temperature control for phase separation, $\mathrm{MgCl}_{2} \cdot 6 \mathrm{H}_{2} \mathrm{O}$ is added to the mixed micelle only after adding SDBS. The analytical advantages of using fluorescence determination are based on in its high sensitivity, proper selectivity and wide linear range. The proposed method is simple and suitable for the routine determination of Rhodamine-B in aqueous media. To evaluate the applicability of the proposed method, it is used to analyze a tap water sample and a contaminated water sample from a dyestuff factory.

\section{EXPERIMENTAL}

Fluorescence spectra and intensity measurements were obtained using a Hitachi F-4500 spectrofluorometer equipped with a $150 \mathrm{~W}$ xenon lamp (Japan). The slit widths of both excitation and emission monochromators were set at $5 \mathrm{~nm}$. The fluorescence spectra were recorded at a scan rate of 1200 $\mathrm{nm} / \mathrm{min}$. All measurements were taken in a $0.7 \mathrm{~mL}$ quartz cell at $25.0 \pm 0.5{ }^{\circ} \mathrm{C}$. A centrifuge (Model TDZ4-WS, Xiang yi Centrifuge Instrument Co., Ltd., China) was used to accelerate the phase-separation process. A pH meter (Model pHS-3C, Shanghai Tianda Apparatus Co., Ltd., China) was used for $\mathrm{pH}$ adjustment. A SHA-B constant-temperature shaker (Changzhou Guohua Electric Appliance Co., Ltd., China) was used to control temperature.

All chemicals were analytical reagent grade and doubledistilled water was used throughout. Rhodamine-B was obtained from Merck (Darmstadt, Germany). The stock solution (0.1 $\mathrm{mg} / \mathrm{mL}$ ) was prepared by dissolving $10 \mathrm{mg}$ of Rhodamine-B in $50 \mathrm{~mL}$ of ethanol and diluting to the mark in a $100 \mathrm{~mL}$ volumetric flask with double-distilled water. A working standard solution was prepared by appropriately diluting the stock solution. SDBS was analytical reagent grade and obtained from Acros Organics. $\mathrm{MgCl}_{2} \cdot 6 \mathrm{H}_{2} \mathrm{O}$ was obtained from Sigma and Beijing Chemical Reagents Company (China).
Procedure: Aliquots of the standard solution were mixed with $1 \mathrm{~mL}$ of Britton-Robinson buffer solution ( $\mathrm{pH} 7$ ) and 0.5 $\mathrm{mL}$ of $2 \%$ SDBS extracting solution before entire mixtures were increased to $5 \mathrm{~mL}$ with double-distilled water, added with $0.6 \mathrm{~g}$ of $\mathrm{MgCl}_{2} \cdot 6 \mathrm{H}_{2} \mathrm{O}$ and poured into a set of graduated centrifuge tubes. The entire mixture was diluted to $5 \mathrm{~mL}$ with water. The prepared solution was kept at for $15 \mathrm{~min}$ in an ice bath for equilibration and then centrifuged for $10 \mathrm{~min}$ at $3500 \mathrm{rpm}$. The separated surfactant-rich phase became a white solid at the bottom of the tubes and the aqueous phase was poured off by inversion. The surfactant-rich phase in the tubes was then diluted with $0.2 \mathrm{~mL}$ of methanol. The diluted surfactant-rich phase was transferred into quartz cells and the fluorescence intensity of Rhodamine-B was measured. The calibration graph was constructed in the same way with studied standard solutions of known concentrations.

\section{RESULTS AND DISCUSSION}

The spectral characteristics of Rhodamine-B and its extrac-tion were studied. As shown in Fig. 2, an aqueous solution of Rhodamine-B had a weak native fluorescence and the maximum excitation and emission wavelengths were located at 557 and $572 \mathrm{~nm}$ (a,a'), respectively. However, the fluore-scence intensity significantly increased when SDBS was added to extract the aqueous solution of Rhodamine-B. In addition, the excitation and emission wavelengths of the extracts moved to shorter wavelengths of 549 and $567 \mathrm{~nm}$ (b, b'), respectively. These modifications in the fluorescence spectra were consi-dered result from complex formation between the investigated Rhodamine-B and SDBS.

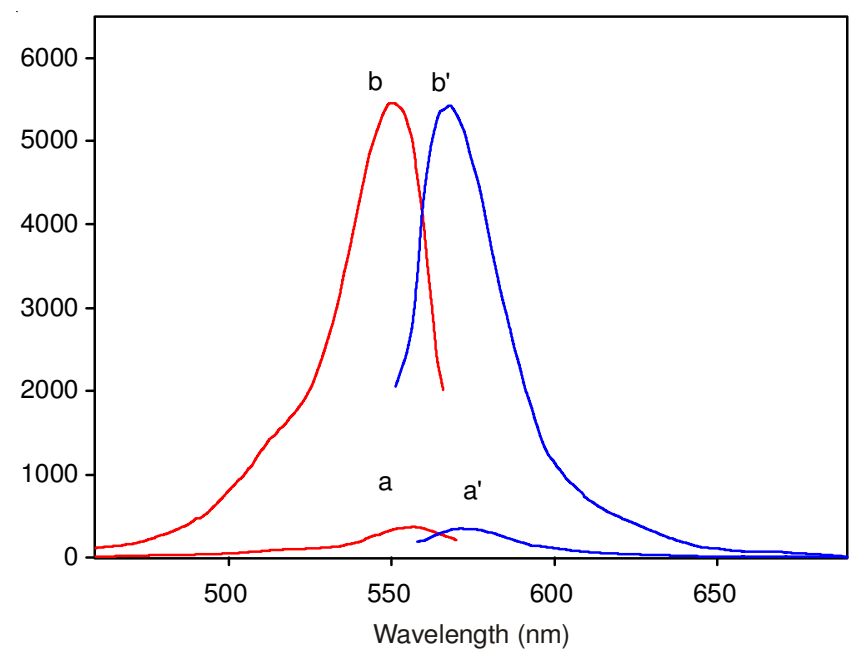

Fig. 2. Fluorescence spectra of RhB and RhB-SDBS. (a,a') fluorescence spectra of RhB, and RhB-SDBS $\lambda_{\text {ex }} / \lambda_{\text {em }}=557 / 572 \mathrm{~nm}$; (b,b') RhB$\mathrm{SDBS}, \lambda_{\mathrm{ex}} / \lambda_{\mathrm{em}}=549 / 567 \mathrm{~nm} ; \mathrm{C}_{\mathrm{RhB}}=8 \mathrm{ng} / \mathrm{mL} ; \mathrm{C}_{\mathrm{SDBS}}=2 \% ; \mathrm{pH}=$ 7.0

Effect of pH: In recently developed CPE methods, schemes based on ionic surfactants are used effectively to extract charged analytes ${ }^{23}$. $\mathrm{pH}$ plays a unique role in neutral zwitterionic state formation, which is responsible for the separation of Rhodamine-B into the surfactant phase and subsequent extraction. The effect of $\mathrm{pH}$ on the extraction of Rhodamine-B from water samples was studied within $\mathrm{pH} 1$ to 
12. Thus, $\mathrm{pH}$ is an important parameter affecting the adsorption of target compounds. The influence of $\mathrm{pH}$ in the CPE of Rhodamine- $\mathrm{B}$ was investigated. The $\mathrm{pH}$ of the standard solution was adjusted by the addition of $1 \mathrm{~mL}$ of buffer solution. The $\mathrm{pH}$ of the buffer solution was varied within the range of 1 to 7 . The results are shown in in Fig. 3. The analytical signal reaches the maximum at $\mathrm{pH} 7$. Therefore, a $\mathrm{pH} 7$ buffer solution was used in subsequent procedures.

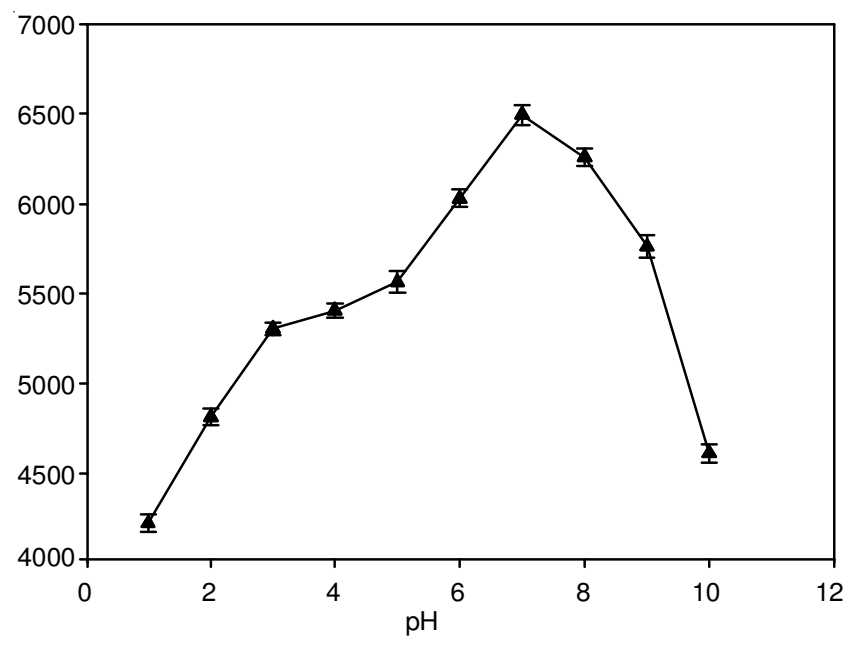

Fig. 3. Influence of $\mathrm{pH}$ on the fluorescence intensity. Experiment condition: $\mathrm{RhB}$ concentration $10 \mathrm{ng} / \mathrm{mL} ; 0.5 \mathrm{~mL}$ of $2 \%$ SDBS; $0.6 \mathrm{~g}$ of $\mathrm{MgCl}_{2} \cdot 6 \mathrm{H}_{2} \mathrm{O}$; equilibration temperature and incubation time, $0{ }^{\circ} \mathrm{C}$ and $15 \mathrm{~min}$; centrifugation time, $10 \mathrm{~min}$; constant volume to 0.2 $\mathrm{mL}$ with methanol

Effect of type and amount of surfactant: Various surfactant systems (CTAB, hexadecylpyridinium bromide hydrate, Tween 20, SDS and SDBS) were tested as extractants of Rhodamine-B and the results were compared. Results indicated that SDBS exhibited better enrichment extraction ability than SDS and both anionic surfactants had better enrichment extraction abilities than the others. The effect of surfactant concentration on CPE is important. The range within which easy phase separation, maximum extraction efficiency and analytical signal can be carried out is narrow. Hence, the variation in extraction efficiency was studied within the surfactant concentration range of $0.1 \mathrm{~mL}$ to $1 \mathrm{~mL}$. Best results were obtained at $0.5 \mathrm{~mL}$ of SDBS, which was thus chosen in all stages.

Effect of electrolytes: The cloud point temperatures of micellar solutions can be controlled by the addition of salts (salting-out effect), alcohols, non-ionic surfactants and organic compounds. An increase in the cloud point of micellar solutions can be controlled by the addition of salts. The effects of $\mathrm{NaCl}$, $\mathrm{BaCl}_{2}, \mathrm{KCl}$ and $\mathrm{MgCl}_{2} \cdot 6 \mathrm{H}_{2} \mathrm{O}$ on the cloud point behaviour of the system were also investigated. Results indicated that the presence of $\mathrm{MgCl}_{2} \cdot 6 \mathrm{H}_{2} \mathrm{O}$ promoted the clouding phenomena. Therefore, the effect of this electrolyte within the range of $0.1 \mathrm{~g}$ to $1 \mathrm{~g}$ was studied. Fluorescence intensity continuously increased until the amount of $\mathrm{MgCl}_{2} \cdot 6 \mathrm{H}_{2} \mathrm{O}$ was $0.6 \mathrm{~g}$, beyond which fluorescence intensity decreased. Thus, $0.6 \mathrm{~g}$ of $\mathrm{MgCl}_{2} \cdot 6 \mathrm{H}_{2} \mathrm{O}$ was deemed optimum.

Effects of equilibration temperature and incubation time: The recovery percentage depends on the time and temperature that the analytes have to interact with the micelles and get into their core. The analyte preconcentration factor and recovery percentage in CPE increases with increased equilibration temperature for phase separation. Similarly, an increase in the CPT leads to a slight decrease in the volume of the surfactant-rich phase. Therefore, the effects of equilibration temperature and time were investigated. The result obtained from Fig. 4 indicated that $0{ }^{\circ} \mathrm{C}$ was suitable for the proposed $\mathrm{CPE}$. The dependence of extraction efficiency on incubation time was studied from 5 to 30 min. Thus, As shown in Fig. 5, an incubation time of $15 \mathrm{~min}$ was deemed optimum.

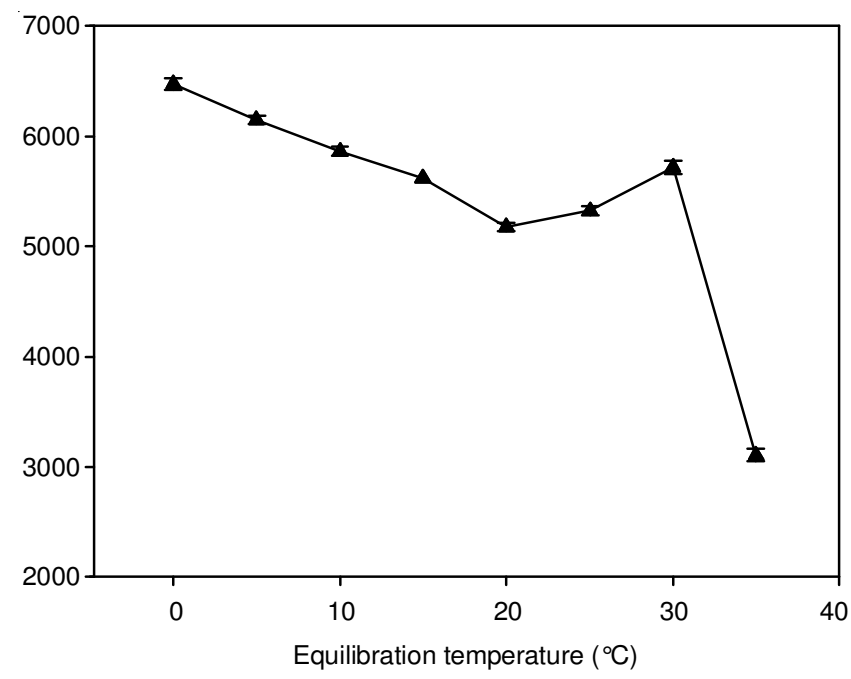

Fig. 4. Influence of equilibration temperature on the fluorescence intensity. Experiment condition: $\mathrm{RhB}$ concentration $10 \mathrm{ng} / \mathrm{mL} ; 0.5 \mathrm{~mL}$ of 2 $\%$ SDBS; $0.6 \mathrm{~g}$ of $\mathrm{MgCl}_{2} \cdot 6 \mathrm{H}_{2} \mathrm{O}$; incubation time, $15 \mathrm{~min} ; \mathrm{pH}, 7$; centrifugation time, $10 \mathrm{~min}$; constant volume to $0.2 \mathrm{~mL}$ with methanol

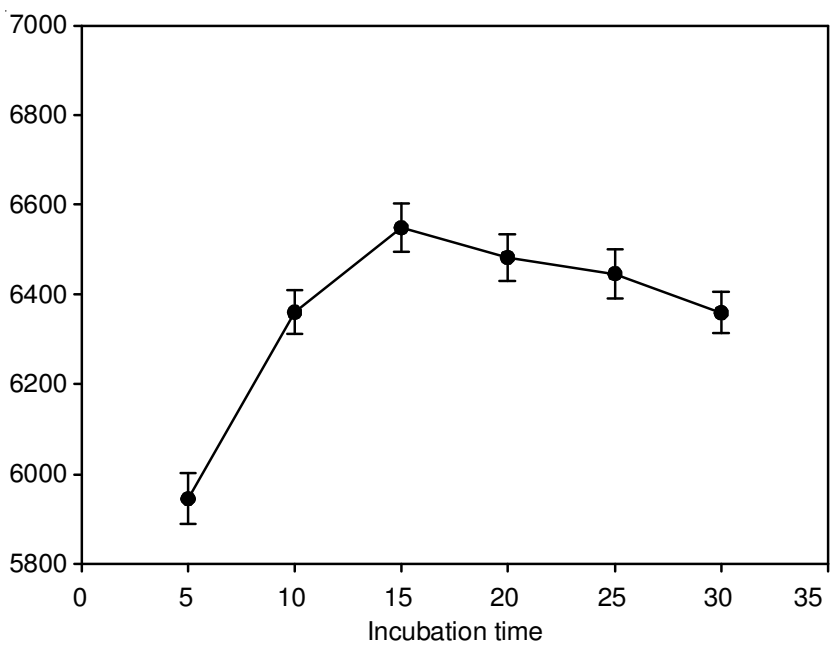

Fig. 5. Influence of incubation time on the fluorescence intensity. Experiment condition: $\mathrm{RhB}$ concentration $10 \mathrm{ng} / \mathrm{mL} ; 0.5 \mathrm{~mL}$ of $2 \%$ SDBS; $0.6 \mathrm{~g}$ of $\mathrm{MgCl}_{2} \cdot 6 \mathrm{H}_{2} \mathrm{O}$; equilibration temperature, $0{ }^{\circ} \mathrm{C}$; $\mathrm{pH}, 7.0$;centrifugation time, $10 \mathrm{~min}$; constant volume to $0.2 \mathrm{~mL}$ with methanol

Effect of centrifugation time: Centrifugation time does not significantly affect micelle formation but accelerates phase separation, in the same sense as in conventional separations of a precipitate from its original aqueous environment. The effect of centrifugation time on extraction efficiency was studied 
from 5 to $30 \mathrm{~min}$. Complete phase separation was achieved for centrifugation times longer than $5 \mathrm{~min}$. Accordingly, a centrifugation time of $10 \mathrm{~min}$ was deemed optimum, with good efficiency for separating both phases and experimental convenience.

Interference studies: The selectivity of the proposed method was studied based on the effect of various chemical species on the determination of Rhodamine-B. Various amounts of other species were added to a solution containing $50 \mathrm{ng} / \mathrm{mL}$ Rhodamine-B and the recommended procedure was imple-mented. An error less than or equal to $\pm 5 \%$ in the absorbance readings was considered acceptable. Table- 1 showed the good selectivity of the procedure. Two similar dyes, fluorescein and Rhodamine $6 \mathrm{G}$, were also acceptable up to 20 and 15 ratios, respectively.

Calibration graph and sensitivity: Under the experimental conditions described, the standard calibration curves for Rhodamine-B were constructed by plotting fluorescence intensity $v s$. concentration. The linear regression equations for Rhodamine-B is listed in Table-2. As shown in Fig. 6ab, the correlation coefficient was 0.9992 , which indicated good linearity. The small value of variance confirmed the small degree of scattering of the experimental data points around the regression line. The lower detection limit (LOD) for each method was determined according to the IUPAC recommendation as follows: $\mathrm{LOD}=\mathrm{KS}_{0} / \mathrm{S}$, where $\mathrm{K}$ is taken as $3, \mathrm{~S}_{0}$ is the standard deviation of the blank, $\mathrm{n}=11$ and $\mathrm{S}$ is the slope of the graph. The method is found to be sensitive and reproducible.

Application: To demonstrate the feasibility of this method, a tap water sample from Linfen city and a contaminated water sample from a dyestuff factory were analyzed. The recovery of Rhodamine-B was calculated by comparing the concentration obtained from the spiked mixtures with those of the pure dye Table-3. Comparison of the results obtained by the currently proposed method with those obtained by reference methods showed ${ }^{11}$ that the accuracy of the proposed method was satisfactory. $F$-test and $t$-test (Table-4) showed no significant difference between the calculated and theoretical values (95\% confidence interval) of both the proposed and reference methods. These results indicated that the precision and accuracy of the proposed method were comparable to those of the reference method. Thus, the proposed method can be
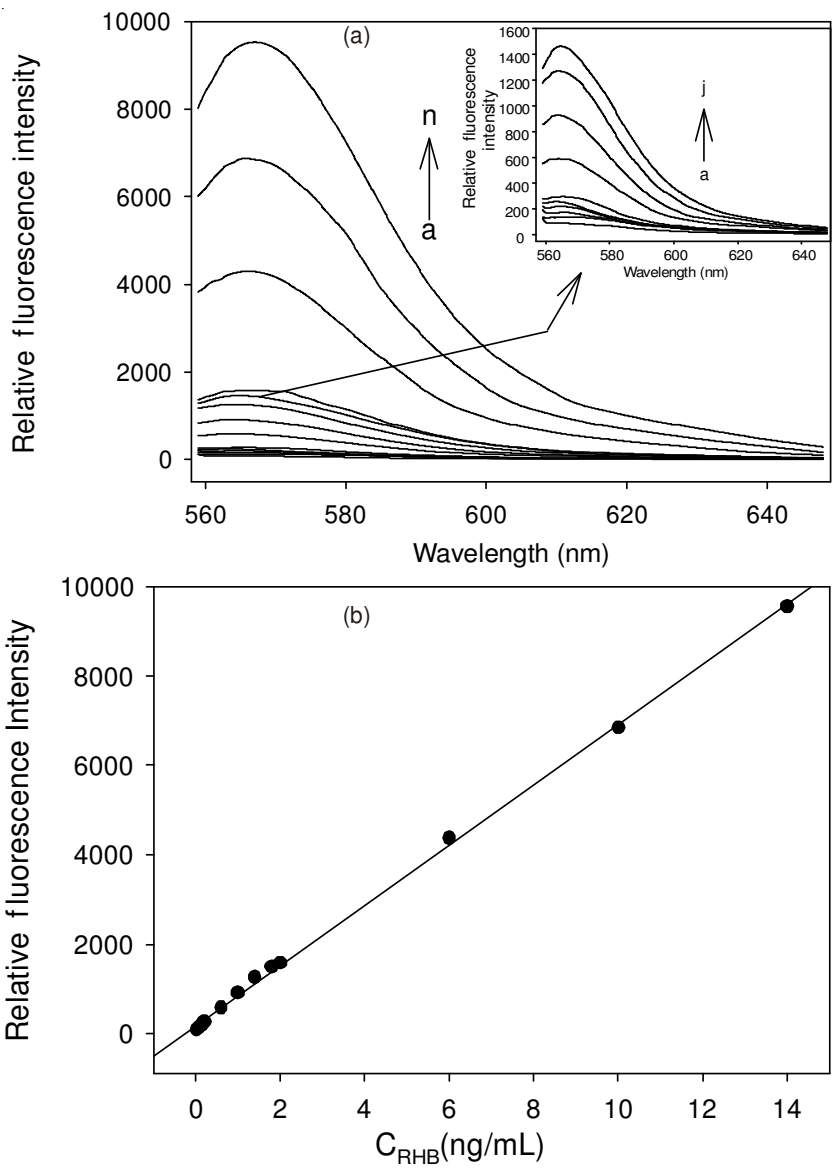

Fig. 6. (a) Fluorescence spectra of RhB concentration. Experiment condition: $\mathrm{C}_{\mathrm{RhB}}(\mathrm{n})=0.02,0.06,0.1,0.14,0.18,0.2,0.6,1,1.4,1.8$, 2, 6, 10, 14 ng/mL, n = a, b, c, d, e, f, g, h, i, j, k, 1, m, n; $0.5 \mathrm{~mL}$ of $2 \%$ SDBS; $0.6 \mathrm{~g}$ of $\mathrm{MgCl}_{2} \cdot 6 \mathrm{H}_{2} \mathrm{O}$; equilibration temperature and incubation time, $0{ }^{\circ} \mathrm{C}$ and $15 \mathrm{~min} ; \mathrm{pH}, 7.0$; centrifugation time, 10 min; constant volume to $0.2 \mathrm{~mL}$ with methanol; (b) Fluorescence spectra of $\mathrm{RhB}$ concentration experiment condition: $\mathrm{C}_{\mathrm{RhB}}(\mathrm{n})=0.02$, $0.06,0.1,0.14,0.18,0.2,0.6,1,1.4,1.8,2,6,10,14 \mathrm{ng} / \mathrm{mL}, \mathrm{n}=\mathrm{a}$, b, c, d, e, f, g, h, i, j, k, 1, m, n; $0.5 \mathrm{~mL}$ of $2 \%$ SDBS; $0.6 \mathrm{~g}$ of $\mathrm{MgCl}_{2} \cdot 6 \mathrm{H}_{2} \mathrm{O}$; equilibration temperature and incubation time, $0{ }^{\circ} \mathrm{C}$ and $15 \mathrm{~min} ; \mathrm{pH}, 7.0$; centrifugation time, $10 \mathrm{~min}$; constant volume to $0.2 \mathrm{~mL}$ with methanol

used as a rapid, simple, sensitive, convenient and practical method for monitoring in Rhodamine-B in various water samples.

\begin{tabular}{|c|c|}
\hline & $\begin{array}{l}\text { TABLE-1 } \\
\text { EFFECTS OF THE INTERFERING SPECIES ON THE RECOVERY OF } 50 \mathrm{ng} / \mathrm{mLOF} \\
\text { RHODAMINE-B FROM THE AQUEOUS SOLUTIONS (<5\% ERROR) }\end{array}$ \\
\hline $\begin{array}{c}\text { Tolerance } \\
\text { Ratio (w/w) }\end{array}$ & Interferent \\
\hline 1000 & $\mathrm{Na}^{+}, \mathrm{Zn}^{2+}, \mathrm{Ba}^{2+}, \mathrm{Ca}^{2+}, \mathrm{Mg}^{2+}, \mathrm{Sr}^{2+}, \mathrm{Sn}^{2+}, \mathrm{Al}^{3+}, \mathrm{Ni}^{2+}, \mathrm{Cu}^{2+}, \mathrm{Cd}^{2+}, \mathrm{Hg}^{2+}, \mathrm{Cl}^{-}, \mathrm{NO}_{2}^{-}, \mathrm{HCO}_{3}^{-}, \mathrm{CH}_{3} \mathrm{O}^{-}, \mathrm{SO}_{4}^{2-}, \mathrm{CrO}_{4}^{2-}, \mathrm{Cr}_{2} \mathrm{O}_{7}^{2-}$ \\
\hline 500 & $\mathrm{~K}^{+}, \mathrm{Pb}^{2+}, \mathrm{Co}^{2+}, \mathrm{Cr}^{3+}, \mathrm{NH}_{4}^{+}, \mathrm{Fe}^{2+}, \mathrm{Fe}^{3+}, \mathrm{F}^{-}, \mathrm{Br}^{-}, \mathrm{I}^{-}, \mathrm{NO}_{3}^{-}, \mathrm{S}_{2} \mathrm{O}_{3}^{2-}, \mathrm{S}_{2} \mathrm{O}_{8}^{2-}, \mathrm{BO}_{3}^{3-}, \mathrm{B}_{4} \mathrm{O}_{7}^{2-}, \mathrm{CH}_{3} \mathrm{COO}^{-}, \mathrm{CO}_{3}^{2-}, \mathrm{C}_{2} \mathrm{O}_{4}{ }^{2-}, \mathrm{HPO}_{4}^{2-}, \mathrm{H}_{2} \mathrm{PO}_{4}^{-}$ \\
\hline $\begin{array}{c}8 \\
15\end{array}$ & $\begin{array}{c}\mathrm{MnO}_{4}^{-} \\
\text {Rhodamine 6G }\end{array}$ \\
\hline 20 & Fluorescein \\
\hline
\end{tabular}

TABLE-2

ANALYTICAL PARAMETER FOR RHODAMINE-B $(\mathrm{n}=11)$

\begin{tabular}{|c|c|c|c|c|c|c|c|c|}
\hline $\begin{array}{l}\text { Analytical } \\
\text { characteristic }\end{array}$ & $\begin{array}{c}\text { Linear } \\
\text { regression } \\
\text { equation }\end{array}$ & $\begin{array}{l}\text { Linear range } \\
(\mathrm{ng} / \mathrm{mL})\end{array}$ & $\begin{array}{c}\text { Slope } \\
\text { standard } \\
\text { deviation } S_{b}\end{array}$ & $\begin{array}{c}\text { Intercept } \\
\text { standard } \\
\text { deviation } S_{a}\end{array}$ & $\begin{array}{c}\text { Mean } \\
\text { square } \mathrm{S}_{0}{ }^{2}\end{array}$ & $\begin{array}{c}\text { Correlation } \\
\text { coefficient } \\
\text { Limit } \\
\end{array}$ & $\begin{array}{l}\text { Limit of } \\
\text { detection } \\
(\mathrm{ng} / \mathrm{mL})\end{array}$ & R.S.D. (\%) \\
\hline Rhodamine B & $\begin{aligned} & \mathrm{y}= 134.9 \mathrm{C}+ \\
& 182.9\end{aligned}$ & $0.2-14$ & 1.12 & 0.76 & 0.023 & 0.9992 & 0.006 & $0.94-2.12$ \\
\hline
\end{tabular}




\begin{tabular}{|c|c|c|c|c|}
\hline & DETERMI & $\begin{array}{c}\text { TABLE-3 } \\
\text { RHODAMINE-B OF WA }\end{array}$ & AMPLE $(n=5)$ & \\
\hline Sample & Added (ng/mL) & Measured value $(\mathrm{ng} / \mathrm{mL})$ & Recovery $(\%) \pm$ S.D ${ }^{a}$ & RSD (\%) \\
\hline \multirow{4}{*}{ Tap } & - & 0 & - & - \\
\hline & 3.0 & 2.96 & $98.7 \pm 0.06$ & 2.12 \\
\hline & 5.0 & 4.96 & $99.2 \pm 0.05$ & 0.94 \\
\hline & 7.0 & 7.02 & $100.2 \pm 0.12$ & 1.68 \\
\hline \multirow{4}{*}{ Sewage } & - & 0.88 & - & - \\
\hline & 3.0 & 3.96 & $102.7 \pm 0.07$ & 1.79 \\
\hline & 5.0 & 5.87 & $99.8 \pm 0.08$ & 1.34 \\
\hline & 7.0 & 7.71 & $97.6 \pm 0.13$ & 1.62 \\
\hline
\end{tabular}

\begin{tabular}{|c|c|c|c|c|c|c|}
\hline \multirow[b]{3}{*}{ Water sample } & \multicolumn{6}{|c|}{$\begin{array}{c}\text { TABLE-4 } \\
\text { DETERMINATION OF THE RHODAMINE-B IN WATER SAMPLE }(\mathrm{n}=5)\end{array}$} \\
\hline & \multicolumn{4}{|c|}{ Present method } & \multicolumn{2}{|c|}{ Literature methods } \\
\hline & Found (ng/mL) & $\begin{array}{l}\text { Equivalent nominal content } \\
\qquad \%) \pm \text { S.D }\end{array}$ & Recovery (\%) & $\operatorname{RSD}(\%)$ & Found (ng/mL) & $\begin{array}{l}\text { Equivalent nominal } \\
\text { Content }(\%) \pm \text { S.D } \\
\end{array}$ \\
\hline Tap & 9.82 & $\begin{array}{c}98.53 \pm 0.64 \\
(\mathrm{t}, 0.79 ; \mathrm{F}, 2.32)\end{array}$ & $98.20 \pm 0.16$ & 1.06 & 9.31 & $97.69 \pm 0.89$ \\
\hline Sewage & 10.13 & $\begin{array}{c}98.36 \pm 0.49 \\
(\mathrm{t}, 0.92 ; \mathrm{F}, 2.51)\end{array}$ & $93.50 \pm 0.14$ & 1.08 & 10.07 & $98.14 \pm 1.21$ \\
\hline
\end{tabular}

\begin{tabular}{|c|c|c|c|c|c|}
\hline \multicolumn{6}{|c|}{$\begin{array}{c}\text { TABLE-5 } \\
\text { CHARACTERISTIC PERFORMANCE OF SOME STUDIES ON THE DETERMINATION OF RHODAMINE-B DYES MATTER }\end{array}$} \\
\hline Methord & $\mathrm{PF}$ & RSD (\%) & Linear range $(\mathrm{ng} / \mathrm{mL})$ & LOD $(\mathrm{ng} / \mathrm{mL})$ & Reference \\
\hline DLLME-UVspectrophotometric & 10 & $1.47-2.88$ & - & 2.39 & 3 \\
\hline CPE-HPLC-Spectrofluorimetry & 2.5 & - & $0.046-100$ & 0.014 & 11 \\
\hline SPE-UV-spectrophotometric & 40 & 5.0 & $250-3000$ & 3.14 & 12 \\
\hline CPE-spectrophotometry & - & $0.87-2.4$ & $5-550$ & 1.67 & 15 \\
\hline CPE-fluorescence Spectroscopy & 25 & $0.94-2.12$ & $0.02-14$ & 0.006 & This work \\
\hline
\end{tabular}

\section{Conclusion}

The anionic surfactant SDBS was demonstrated to be useful in the extraction of Rhodamine-B from aqueous environmental samples by anionic surfactant micelle-mediated extraction prior to fluorescence spectrophotometry. Fluorescence intensities showed good linear relationships with the concentration of SDBS. The proposed procedure was compared with methods found in literature (Table-5) and the detection limit and preconcentration factor of Rhodamine-B were found to be superior to those obtained using preconcentration and separation techniques for analyses. The results clearly showed the potential and versatility of this method for monitoring RhodamineB spectrophotometrically in various water samples.

\section{ACKNOWLEDGEMENTS}

This work was supported by the National Natural Science Foundation of China (No. 21171110) and the Research Fund for the Doctoral Program of Higher Education of China (No. 20091404110001).

\section{REFERENCES}

1. R.W. Mason and I.R. Edwards, J. Chromatogr. B, 491, 468 (1989).

2. R. Jain, M. Mathur, S. Sikarwar and A. Mittal, J. Environ. Manag., 85, 956 (2007).
3. C. Franke, H. Westerholm and R. Niessner, Water Res., 31, 2633 (1997).

4. L. Gagliardi, D. Orsi, G. Cavazzutti, G. Multari and D. Tonelli, Chromatographia, 43, 76 (1996).

5. C. Desiderio, C. Marra and S. Fanali, Electrophoresis, 19, 1478 (1998).

6. C.C. Wang, A.N. Masi and L. Fernández, Talanta, 75, 135 (2008).

7. M.Y. Choudhry, J. Forensic Sci., 36, 366 (1991).

8. P. Biparva, E. Ranjbari and M.R. Hadjmohammadi, Anal. Chim. Acta, 674, 206 (2010).

9. H. Cheng, B. Li and C.R. Zhan, Food Sci., 4, 052 (2010).

10. T. Iqbal, M. Kinjo and T.C. Dowling, J. Chromatogr. B, 814, 259 (2005).

11. M. Alesso, G. Bondioli, M.C. Talío, M.O. Luconi and L.P. Fernández, Food Chem., 134, 513 (2012).

12. M. Soylak, Y.E. Unsal, E. Yilmaz and M. Tuzen, Food Chem. Toxicol., 49, 1796 (2011).

13. J.W. Hofstraat, M. Steendijk, G. Vriezekolk, W. Schreurs, G.J.A.A. Broer and N. Wijnstok, Water Res., 25, 883 (1991).

14. T.A. Khan, S. Dahiya and I. Ali, Appl. Clay Sci., 69, 58 (2012).

15. N. Pourreza, S. Rastegarzadeh and A. Larki, Talanta, 77, 733 (2008).

16. R. Sjöback, J. Nygren and M. Kubista, Molec. Biomolec. Spectrosc., 51, L7 (1995).

17. F. Merino, S. Rubio and D. Pérez-Bendito, J. Chromatogr. A, 998, 143 (2003).

18. C. Padrón Sanz, R. Halko, Z. Sosa Ferrera and J.J. Santana Rodríguez, Anal. Chim. Acta, 524, 265 (2004).

19. J. Shen and X. Shao, Anal. Chim. Acta, 561, 83 (2006).

20. W.L. Hinze and E. Pramauro, Crit. Rev. Anal. Chem., 24, 133 (1993).

21. Z. Wang, F. Zhao and D. Li, Colloids Surf. A, 216, 207 (2003).

22. Q. Li, X. Yao, X. Chen, M. Liu, R. Zhang, X. Zhang and Z. Hu, Analyst, 125, 2049 (2000).

23. S.P. Liu, Z.F. Liu and M.I.N.G. Li, Acta Chim. Sin., 53, 1178 (1995). 